\title{
Jesuits from Asia-Pacific in the Time of Laudato si': Reconciliation with Creation
}

\author{
Pedro Walpole, S.J. \\ Jesuit Conference Asia-Pacific, Quezon City \\ pedroecojcap@gmail.com
}

\begin{abstract}
Jesuit Conference Asia-Pacific established a "Reconciliation with Creation," a comprehensive program that aims to enable greater environmental awareness and participation in caring for all forms of life. As part of this program, Jesuit pastoral ministries with the poor and beyond are integrating social and ecological objectives. Meanwhile, Jesuit schools are embarking upon a new learning curve with many new social engagements and technologies that may enact greater ecological integration and accountability. Likewise, as part of this initiative, Jesuit communities themselves are learning to audit their consumption and waste. Climatic events, as those that have devastated many different communities that this conference represents, are currently the focus of many Jesuit institutions as they seek to develop protocol beyond relief to disaster risk reduction (DRR). Accordingly, in order to address this urgent challenge, sustainability science needs to adapt so that it becomes problem-focused, and a critical element in this endeavor is the capacity of Jesuit institutes to network and collaborate with others. Grounded in gratitude and engaging with hope, "Reconciliation with Creation" is essentially an invitation to act that concurrently seeks to gradually deepen the experience of the sacred.
\end{abstract}

* Pedro Walpole, S.J. (b.1955) is the coordinator of "Reconciliation with Creation" for the Jesuit Conference Asia-Pacific and the director of research at the Institute of Environmental Science for Social Change in the Philippines. He is a practitioner in sustainable environment and community land management in Southeast Asia. Pedro lives with the Pulangiyen, an upland indigenous community in northern Mindanao, where he also directs an integrated culture-based education through the Apu Palamguwan Cultural Education Center.

(C) WALPOLE, 2016 | DOI 10.1163/22141332-00304004

This is an open access article distributed under the terms of the Creative Commons Attribution-

Noncommercial 4.0 Unported (CC-BY-NC 4.0) License. http://creativecommons.org/licenses/by-nc/4,0/2623 01:43:03PM 


\section{Keywords}

Asia-Pacific - reconciliation - healing - creation - eco audit - lifestyle - disaster risk reduction - integral ecology

\section{Introduction: The Asia-Pacific Context}

While, as a whole, the movement for environmental research and ecological action across the Jesuit Conference Asia-Pacific (JCAP) takes many forms, as Jesuit works are only beginning to engage these concerns and still have much to learn. ${ }^{1}$ This article focuses on the trend amongst Jesuits and their collaborators towards greater environmental awareness and the urgent need to communicate and work with others strategically and more broadly for the sake of greater ecological accountability and sustainability. In style and form, this is neither a scholarly article presenting an argument for Jesuit involvement nor an academic review of environmental research nor an assessment of what has already been achieved. Critical responses to environmental issues-it should be stated-are not only occurring through scientific endeavor alone, but also are driven by personal and collective commitment and, in most instances, are not yet sufficiently reflected upon to be academically scrutinized.

For the past several decades, several Jesuit social centers have explicitly articulated an environmental concern, while a concurrent concern for the people, land, and resources are also manifest. In the 1970s, the opposition to the Chico Dam in the Cordillera region of the northern Philippines, for instance, indicates the sort of resistance by communities, with whom the church was also present, to forms of cultural and environmental exploitation. ${ }^{2}$ Pastoral works are typically enacted with emphasis upon the integral relation of people, livelihood, and land, and so efforts towards agrarian reform or the conservation campaigns that confront mining corporations are now explicitly connectingto a certain degree - faith and creation. At this stage, however, such programs seldom elaborate and explain the faith in terms of integral ecology.

1 See United Nations Environment Programme (UNEP), "Global Environment Outlook-5: Environment for the Future We Want," ed. Bart Ullstein et al. (Valletta, Malta: Progress Press Ltd., 2012); Peter King and Lailai Li, "Asia and the Pacific," 259-88, http://www.unep.org/geo/ geo5.asp (accessed June 10, 2016); "With Passion for Environmental Justice: Response of the Society of Jesus to "Reconciliation with Creation," Promotio iustitiae 110 (2013): 40-49, http:// www.sjweb.info/documents/sjs/pj/docs_pdf/PJ_110_ENG.pdf (accessed June 10, 2016).

2 See Francisco F. Claver, S.J., The Stones Will Cry Out: Grassroots Pastorals (Maryknoll, NY: Orbis Books, 1978). 
Furthermore, in the region's schools and universities, many programs run by individual faculty or departments challenge students both academically and socially in their assessment of human interaction with the environment. Normatively, these programs emphasize the need for more sustainable management of resources, and in accordance the issue of transparency regarding donations and grants - whether by individuals or corporations - to these Jesuits institutions is increasingly being raised. In similar vein, greater scrutiny is directed towards institutional investments, particularly in the mining industry and other energy sectors. Subsequently, such close inspection of the institutional fabric of the Society of Jesus is generating an impetus to subject the full range of Jesuit operations, such as retreat houses and university campuses, to comprehensive environmental auditing. The region's Jesuit institutions, schools, and communities have initiated environment-oriented activities with the purpose of further cultivating and incorporating core commitment towards care for creation as a kind of reconciliation into their collective mission. This form of reconciliation with the land and natural resources may be slow, yet many are deeply encouraged by the affirmative wisdom of the Holy Father, Pope Francis, in his encyclical, Laudato si', and seek to share with others the challenge and the joy of deepening our prayer with activities that reflect care for all form of life. ${ }^{3}$

Presently, Jesuits of JCAP are in the process of learning that environmental studies, as a field of study that addresses problem-focused needs, elevates their institutional ability to network in an interdisciplinary and a global manner. Such inquiry also emphasizes the social and contextual elements that might better ground their research assumptions. In this way, Jesuits may provide a better response to their universal mission through an approach that is concurrently global and contextual. ${ }^{4} \mathrm{~A}$ stress upon achieving greater cohesion within the region or a global identification of key areas for collaboration might intensify an ethical response at various levels. This, in turn, requires significant attention to the internal and external factors that can potentially enhance capacity for international networking. ${ }^{5}$ The challenge to draw as many responsive and active people and institutions as possible into collaboration could

3 Francis, Laudato si', May 24, 2015, http://w2.vatican.va/content/francesco/en/encyclicals/ documents/papa-francesco_20150524_enciclica-laudato-si.html (accessed June 10, 2016).

4 General Congregation 35, Decree 5, "Governance at the Service of Universal Mission," http:// www.sjweb.info/35/documents/Decrees.pdf (accessed June 10, 2016).

5 "Networking in Order to Respond Better to Our Mission: Networks of the Social Apostolate in the Society of Jesus," Promotio iustitiae 113 (2013): 68, http://www.sjweb.info/documents/sjs/ pj/docs_pdf/PJ_113_ENG.pdf (accessed June 10, 2016). 
instill the multiple perspective that would be necessary in order to see clearly beyond the parochial engagements and academic silos, which might inhibit such a global enterprise. ${ }^{6}$

In 2010, JCAP, under the leadership of Mark Raper, S.J. (b.1942), began to promote reconciliation with creation. ${ }^{7}$ Shortly thereafter Healing a Broken World was published, as an apostolic response to environmental degradation that envisioned the integral reconciliation sought with God, with neighbor, and with creation, and as a resource that presently constitutes the guiding document with institutional recommendations. ${ }^{8}$ The subsequently published document, Our Environmental Way of Proceeding (OEWP), provides practical steps and reflections on how those interested in environmental justice might proceed in participating with shared social and environmental endeavors. ${ }^{9}$ As a result, this ecological strategy is a matter of concern for the whole conference and seeks expression through the following modes: our institutions and lifestyles; formation of young people, lay and religious; and governance of natural and mineral resources. $O E W P$ is essentially a spiritual and social invitation to take up these three themes as a basis for advancing this particular ecological strategy and its vision of a renewed relation with the land.

JCAP identified ecology, in particular, as one of the conference's priorities partly due to the region's history of environmental disasters. Its attention towards ecology also encompasses the ethical challenges of social exclusion, and the growing impact of climate change upon livelihoods, and thus explicitly affirms the desire to respond to a world at risk. The major superiors and provincials of JCAP in a recent statement on Laudato si' encouraged Jesuits in Asia-Pacific to become involved in especially identifying water concerns, planting vegetation, and recycling as practical priorities. ${ }^{10}$ Such concerns and

6 Eric B. Kennedy, and Jacqueline Ho, "Discursive Diversity in Introductory Environmental Studies," Journal of Environmental Studies and Sciences 5, no. 2 (2015): 200-6.

7 Jesuit Asia Pacific Conference, "Reconciliation with Creation: Strategy for 2015-2019" (January 2015), http://www.sjapc.net/what-we-do/reconciliation-creation (accessed June 10, 2016). For the publication, see "Jesuit Asia-Pacific Conference-Task Force on Ecology: Environmental Science for Social Change; Reconciling with Creation," http://www.ecoje suit.com/reconciling-with-creation/7764/ (accessed June 10, 2016).

8 Promotio iustitiae 106, no. 2 (2011), 30, http://www.ecojesuit.com/jesuit-response-to-envi ronmental-and-ecological-challenges-healing-a-broken-world/1427/.

9 Environmental Way of Proceeding, August 2012 (revision), 185. http://www.ecojesuit.com/ wp-content/uploads/2015/04/7-Environmental-Way-of-Proceeding.pdf (accessed June 10, 2016).

10 JCAP, “Statement on Laudato si," July 20, 2015, http://sjapc.net/content/statement-lauda to-si\%E2\%80\%99 (accessed June 27, 2016). 
agendas may be coordinated most effectively through management practices that could be developed in each Jesuit community or institute.

In these documents, three specific invitations — or "calls" - to engage are elaborated, namely the call to respond to a world at risk, ${ }^{11}$ the call to dialogue with sustainable science and values, ${ }^{12}$ and the call to inner life and particularly a simple lifestyle. Several strategic responses are also disseminated in the document in an effort to encourage Jesuits and those working with them to deepen their ecological engagement and to collaborate more broadly with others. This, however, is not meant to be conveyed or framed in the sense that the Jesuits know what to do-far from it—but in a humble gesture to exhort Jesuits to reflect in terms of ecology and how they could participate and contribute beyond the parameters of the Society and its institutions. Laudato si' subsequently should be acknowledged for having intensified the need for all to care for creation, and significantly deepened the commitment of many to act. In the sections that follow each of the specific invitations-or calls-are elaborated.

\section{A Call to Respond to a World at Risk}

The Asia-Pacific region and JCAP — as previously stated — has witnessed a series of climatic catastrophes in recent years. This survey of events, with specific reference to the role of Jesuits, can provide context for this eco-networking trajectory, while highlighting the development of DRR as an integral part of the conference's strategy, thereby grounding this particular ethical way of proceeding in an ecological manner.

In 1991, when Tropical Storm Thelma brought devastation to Ormoc City in the Philippines, the national media-coverage in the aftermath described the occurrence as a freak event. ${ }^{13}$ As a tropical storm, Thelma lacked high winds that are typical of a typhoon, and so traveled slowly down the length of two adjacent rivers delivering substantial rainfall. Consequently, the accumulated flow caused a surge particularly where the two tributaries merged just east of

11 JCAP, "A Call to Respond to a World at Risk," October 2015, http://www.ecojesuit .com/wp-content/uploads/2014/11/Call-to-respond-to-a-world-at-risk.jpg (accessed June 13, 2016).

12 JCAP, "A Call to Share Inner Life and Simple Lifestyle" (May 2016), http://www.ecojesuit. com/wp-content/uploads/2014/11/JCAP-Call-to-Inner-Life.pdf (accessed June 27, 2016).

13 NOAA's Top Global Weather, Water and Climate Events of the 2oth Century, http://www .noaanews.noaa.gov/stories/images/global.pdf (accessed June 10, 2016). 
the city. The occurrence of this storm, rather than a typhoon, and the watershed drainage patterns, which flowed eastward from mountainous elevations onto highly populated coastal plains, provide the basic lessons and expectations for disasters in the subsequent decades, until the present.

The 2004 tsunami that struck Banda Aceh, Indonesia, brought a global response, and Jesuit Refugee Services Indonesia, especially through the work of Adrianus Suyadi, S.J. (b.1965), supplied critical relief and support. This experience presents some crucial lessons to be learnt, not least of which is that in the aftermath of such catastrophic events a recovery program tends to require two years in order to be fully operational.

In 2008, Typhoon Nargis hit the Irrawaddy Delta, in Burma, where Amalraj Chinnappen, S.J. (b.1953), coordinated the appeal, along with Nay Myo Htet, S.J. (b.1981), in immediate response to some of the delta's localized needs. In particular, they assisted some farmers so that they were eventually able to produce again, as well as various communities in order to sustain their schools. For these efforts, the challenge to develop capacity and to train community leaders and local officials, who could take greater responsibility for improved community adaptation and response, inherently becomes a tactical move for greater social inclusion. According to this rationale, until the poor are able to take responsibility for their own household safety and wellbeing, they are constantly at risk and thus might suffer gravely. ${ }^{14}$

After the 2011 tsunami that collided with the Japanese city of Fukushima, the prospect of the unknown consequences, specifically those associated with nuclear disasters, raised an added element of complexity that pertains to both contaminated lands and waters in the Pacific Ocean's currents..$^{15}$ Jesuit social action centers in Japan and Korea are still facilitating campaigns that advocate for the end of nuclear power and that highlight the associated risks as the operating-life of many of the nuclear plants are being extended. ${ }^{16}$ As part of

14 Another similar example of this kind of response can be found in Indonesia, where Greg Soetomo, S.J. (b.1964), is very active with the scholastics in ecological engagements. Christoforus Bayu Risanto, S.J. (b.1981), and other scholastics responded when Mount Merapi erupted in Java in 2010.

15 Teppei J. Yasunaria et al., "Cesium-137 Deposition and Contamination of Japanese Soils due to the Fukushima Nuclear Accident," Proceedings of the National Academy of Sciences 108, no. 49 (2011): 19530-4; http://www.pnas.org/content/108/49/19530.full.pdf (accessed June 10, 2016).

16 Pedro Walpole, S.J. with Francis Mun-su Park, S.J., "Ecological and Social Concerns in Korea: Areas for Active Collaboration," EcoJesuit, August 15, 2015, http://www.ecojesuit.com/ecological-and-social-concerns-in-korea-areas-for-active-collaboration/ 8534/ (accessed June 10, 2016). See also n. 47. 
these efforts, in 2014, Cho Hyun-chul, S.J. (b.1959), led a pilgrimage from Busan to Seoul for greater nuclear awareness amongst Koreans.

Out of these experiences, in 2011, when Typhoon Washi hit northern Mindanao in the Philippines, Roberto Yap, S.J. (b.1959), as the president of Ateneo de Cagayan-Xavier University, responded with area-coordination and housing initiatives, along with his team that included Hilly Ann Roa-Quiaoit, Dexter Lo, and others. Accordingly, a Jesuit research institute, Environmental Science for Social Change (ESSC), the first of its kind in the region, focused on analyzing the volume, time, distribution, and accumulation of rainfall in Barangay Carmen, a district in Cagayan de Oro City, in order to assess the risks and then to discuss with the community so that they might understand their desired responses. ${ }^{17}$

In 2013, with the disaster that followed Typhoon Haiyan and that struck the central Philippines, several individual Jesuits and affiliated institutions responded in enacting the disaster risk reduction (DRR) protocol. Participants in this effort included:Xavier Alpasa, S.J. (b.1968), Bernie Aton, and Firmo Bargayo, S.J. (b.1978), of Simbahang Lingkod ng Bayan (SLB); Jose Ramon Villarin, S.J. (b.196o), and Jaime Hofileña of Ateneo de Manila University; Antonia YuloLoyzaga and Gemma Narisma of the Manila Observatory, and Sylvia Miclat and Dallay Annawi of EsSC. As this team learnt, foundational for developing a strategy of mitigation and preparedness is the understanding of "ordinary time," which is to say that annually there is a period of six months when there is a limited threat concerning weather events and so there might be little action. Although the disaster management cycle is generally described as having four phases - mitigation, preparedness, response, and recovery ${ }^{18}$ - there is an increasing realization of a fifth phase, namely re-design. This particular stage represents a period of coordination that strives for more resilient construction and development of infrastructure than had existed before the disaster so that the local environs might be able to withstand such events in the future, and thus not be completely debilitated. ${ }^{19}$

17 Regarding the Philippine Working Group Disaster Risk Assessment in Barangay Carmen, Cagayan de Oro City, see Joseph Labrador, "CDo mayor Oscar Moreno and key city officials support ESSC-XU initiative to assess disaster risks in Barangay Carmen," Environmental Science for Social Change (July 13, 2013), http://essc.org.ph/content/cdo -mayor-oscar-moreno-and-key-city-officials-support-essc-xu-initiative-to-assess-disas ter-risks-in-barangay-carmen/ (accessed June 27, 2016).

18 Hyogo Framework for Action 2005-2015: Building the Resilience of Nations and Communities to Disasters (HFA), http://www.unisdr.org/we/coordinate/hfa (accessed June 10, 2016). un World Conference on Disaster Risk Reduction, March 2015. Issue Brief: Reconstructing after disasters: Build Back Better, Ministerial Roundtable. Sendai, Japan, March 14-18, 2015, 
The United Nations Sendai Framework for Action more broadly outlines the work required from various stakeholders in order to reduce disaster losses, outline priority actions, and present guiding principles. The goal of this framework is the principles and means for reducing disaster losses by 2030 especially through the objective of building resilient communities and nations in the face of such climatic events. ${ }^{20}$ In the Philippines, Jesuit institutions play a particularly important role in this process as a catalyst for engagement and also as a contributor for regional development regarding capacity networking.

Both flooding and landslides, those types of urgent practical issue that warrant such levels of preparedness, are especially problematic in the developing countries of the Asia-Pacific region, where there tends to be an abundant rainfall in highly populated places. ${ }^{21}$ Per the global consensus about disasters and relief, projects of rehabilitation should be extended for another year or two after the climatic event in order to simply exceed beyond the most basic goals of relief. Still, as indicated above, even after the second year-and this is especially evident in more rural areas-many of the social problems that revolve around re-constructing houses, communities, and basic services usually persist. In a recent review of post-disaster recovery by Asian Development Bank ( $\mathrm{ADB}$ ), the former director of international relations for the Agency of the Rehabilitation and Reconstruction of Banda Aceh and Nias in Indonesia, Heru Prasetyo, outlined some lessons of the Indian Ocean tsunami that struck Banda Aceh. ${ }^{22} \mathrm{He}$ observed the similarities with reports of typhoon Haiyanlocally called Yolanda-that indicated how "Year 2" qualified as the most difficult and that the period of rehabilitation and recovery endures well beyond the point when international attention and relief halts. ${ }^{23}$ With the increasing

http://www.wcdrr.org/uploads/Reconstructing-after-disasters-Build-back-better.pdf (accessed June 10, 2016).

20 Sendai Framework for Disaster Risk Reduction, http://www.unisdr.org/we/coordinate/ sendai-framework, (accessed June 10, 2016).

21 United Nations Framework Convention on Climate Change (UNFCC), 2006. Climate Change: Impacts, Vulnerabilities and Adaptation in Developing Countries, https://unfccc .int/resource/docs/publications/impacts.pdf, (accessed June 10, 2016).

"The Agency of Rehabilitation and Reconstruction of Aceh and Nias," presentation at the International Forum on Tsunami and Earthquakes, Kobe, Japan, January 2007, http:// www.recoveryplatform.org/assets/meetings_trainings/international\%2oforum\%20 on\%2otsunami\%2oand\%2oearthquake/c3.pdf (accessed June 27, 2016).

23 ADB, Proceedings of the Regional Knowledge Forum on Post-Disaster Recovery: 20-21 October 2015, Asian Development Bank (Manila: Asian Development Bank, 2015), 5. See online at: http://www.adb.org/sites/default/files/publication/176471/proceedings-forum -post-disaster.pdf, (accessed June 10, 2016). 
incidents of more intense storms and other climatic hazards, stakeholders are actively seeking opportunities to respond to such needs by recognizing and facilitating capability training in disaster event warning and also an evacuation strategy, in which the ability to interpret and utilize scientific information is expanded. ${ }^{24}$

An informal Jesuit research network is developing that analyzes the advent of all storms and typhoons that might afflict Asia-Pacific. This network simultaneously employs such capabilities to develop greater social preparedness in order to circumvent fear and confusion by discussing these hazards and improving evacuation strategies. ${ }^{25}$ Jesuit universities and institutions in the Philippines, in particular, are formulating a response in this manner by tracking typhoons and depressions, and by discerning who would be best positioned locally to coordinate a Jesuit response - were it to be agreed upon to act - and then to activate effective connections with the government and other types of agencies.

Most Jesuit involvement, however, does not come from scientific analyses of the dilemmas or from policy development and planning, but rather from involvement in developing local livelihoods and cultivating leadership development. ${ }^{26}$ In recent years after a period of relief, it has become typical of post-disaster activities to increasingly foster deeper engagement by responding with ecological concerns of resilience. Thus, on the one hand, there is the urgent need to address the social vulnerability of households, which is determined by people's economic insecurity and substandard housing conditions. ${ }^{27}$ On the other hand, there is also the pressing need to address ecosystem functionality, which is to say the natural functioning of watersheds that are currently compromised due to deforestation, infrastructure development, and urbanization. As a consequence of these environmental and social trends, the disastrous state of the landscape poses an ever greater risk.

These contexts necessarily require a type of sustainability science that is problem-focused, and thus far more interactive. It is critical that such an

24 United Nations, Reducing Disaster Risks through Science: Issues and Actions; The Full Report of the ISDR Scientific and Technical Committee 2009 (Geneva: UNISDR Secretariat, 2009), http://www.unisdr.org/files/11543_STCReportlibrary.pdf (accessed June 10, 2016).

25 JCAP, "A Call to Respond to a World at Risk," October 2015, http://www.ecojesuit.com/wp -content/uploads/2014/11/Call-to-respond-to-a-world-at-risk.jpg (accessed June 13, 2016).

26 "Livelihood," which is used throughout this article, distinct from a job that is simply a means of employment for subsistence. Instead livelihood usually entails rural, farming, or fishing, and it is basically self-employment that requires natural resources, though there are urban equivalents.

27 For further clarification of the terminology that surrounds "social vulnerability," see UNISDR, https://www.unisdr.org/we/inform/terminology (accessed June 10, 2016). 
approach does not aim at a singular solution that would be superimposed on all situations, but instead can account for and operate with the given circumstances, which is to say both the physical locales and the social realities. ${ }^{28}$ The capacity of Jesuit institutes to adequately network is especially crucial in this effort. The Jesuit Filipino province, for instance, now has a protocol for collaboration amongst Jesuit institutions and with other national and local organizations, which reflects a significant development in capacity building. In contrast, previous responses focused on relief in those communities, with whom where Jesuit institutes were already familiar either through staff involvement or congenial student program outreach. Yet now with a broader DRR and management program, the responses are becoming more comprehensive and integrative of other Jesuit organizations and in collaboration with local governments and civil institutions. As disasters are no longer viewed as merely reactive situations, full-year planning is currently underway and there is greater opportunity for engaging more people and resources, while developing responses that might anticipate such prospective large-scale problems.

The primary point of chronicling of this line of Jesuit involvement is to demonstrate and underline that people and institutes can be proactively engaged at a basic level of response, as part of the international operation that seems to be crucial for such a moral and global task that climate change presents. On a basic psychosocial level it is essential that Jesuits realize that they can become involved without a particular expertise and also that those who are presently coordinating institutions and networks could have a much greater role in contributing to the whole DRR process. From a regional perspective, the Society of Jesus intends to reach and coordinate with those in the best position to respond locally, which is not only an international priority of JCAP, but also of Red Xavier. ${ }^{29}$

\section{A Call to Dialogue on Sustainability Science and Values}

In the environmental and social encyclical Laudato si', the Holy Father's urgent appeal for a "new dialogue about how people are shaping the future of our

28 Fiona Miller et al., "Resilience and Vulnerability: Complementary or Conflicting Concepts?," Ecology and Society 15, no. 3 (2011), article 11: http://www.ecologyandsociety.org/ vol15/iss3/art11/ (accessed June 10, 2016).

29 See the aforementioned Healing a Broken World and Our Environmental Way of Proceeding; see also JCAP, "Last Update on JCAP's Strategy on Ecology," http://sjapc.net/content/ update-jcap\%E2\%80\%99s-strategy-ecology (accessed June 13, 2016). For the latter, see the Xavier Network, http://www.netxavier.org (accessed June 10, 2016). 
planet" emphasizes the "need [for] a conversation which includes everyone, since the environmental challenge we are undergoing, and its human roots, concern and affect us all." ${ }^{30}$ The fundamental starting-point for such a conversation should highlight the ecological limits, or "planetary boundaries," that we are presently confronting.

A cohort of representatives from Jesuit social centers gathered for the 2015 Stockholm Dialogue, which offered a formal response to Laudato si', on the challenge of sustainability and values. The convenors stated frankly: "Science shows us the planetary boundaries of our natural and physical world and where we exceeded the thresholds, though there is still much to be better defined."31 These boundaries are partially experienced in particular terrains that people inhabit. Although specific immediate concerns that communities do experience locally may not be critical or urgent on the global level, those concerns would obviously be interconnected within a broader pattern of events. For instance, in the Asia-Pacific region, the present $2015^{-16}$ drought that is the result of El Niño, which seems to correlate with the significant rise in global temperatures, is the most critical issue. ${ }^{32}$ The representatives at the Stockholm Dialogue agreed that it is still imperative to motivate and sustain local endeavors in support of the sustainability of the people in their particular contexts, and that the presence of Jesuit centers in these contexts can facilitate sustainable agendas.

For a specific illustration, a history of Jesuit observatories might highlight the importance given to areas of research that address specific environments and climates. The Observatorio Meteriológico de Manila on the campus of Ateneo de Manila University continues in this Jesuit tradition having celebrated

3o Francis, Laudato si', n. 14.

31 "The Stockholm Dialogue," Ecojesuit, http://www.stockholmdialogue.ecojesuit.com/ (accessed June 10, 2016), with the official proceedings of the symposium. For the actual agenda of the "Dialogue on Sustainability Science and Values: 'The Stockholm Dialogue," Stockholm (Sweden), November 24-25, 2015, https://www.kth.se/polopoly_fs/1.607306!/ Stockholm\%2oDialogue-program_FIN.pdf (accessed June 10, 2016). For further information on the key phrase, "planetary boundaries," see Johan Rockström et al., "Planetary Boundaries: Exploring the Safe Operating Space for Humanity," Ecology and Society 14, no. 2 (2009), article 32, http://www.ecologyandsociety.org/voli4/iss2/art32/ (accessed June 10, 2016). Johan Rockström et al., "A Safe Operating Space for Humanity," Nature 461 (2009): 472-75, http://www.nature.com/news/specials/planetaryboundaries/index.html (accessed June 10, 2016).

32 National Oceanic and Atmospheric Administration (NOAA), Global Analysis: State of the Climate Reports (February 2016)," https://www.ncdc.noaa.gov/sotc/global/201602 (accessed June 10, 2016). 
150 years of research in $2015 .^{33}$ Today research at this institution includes upper atmospheric dynamics, regional climate systems, climate change assistance, and solid earth dynamics under the directorship of Antonia Yulo-Loyzaga. The research of Jose Ramon Villarin, for example, focuses on air quality dynamics showing that emissions in the metropolitan area of Manila are primarily emitted from the energy sector and can also attributed to the waste sector. ${ }^{34}$ In recent years, many of the region's universities have started similar departments of environmental science. ${ }^{35}$

In 1997, Environmental Science for Social Change (ESSC) was set up in recognition of the need to "turn telescopes to earth," so to speak, and to confront the damage that the status quo, expressly the unsustainable pursuit of economic development and natural resource depletion, was having upon both people and the land. Essc recognized the need for a problem-focused science that responds to local concerns, especially of those on the margins, and that such a scientific approach can subsequently guide the social change that is needed through effective communication. The remote sensing laboratory, which focuses on forest cover loss and watershed delineation, represents this sort of scientific approach to environmental change incorporating the needs of disaffected communities and highlighting social concerns for the sake of an integral ecological response. Pedro Walpole, S.J. (b.1955), along with Jose Andres Ignacio, developed geomatics to survey changes in land use in the Philippines and other parts of Asia. ${ }^{36}$ Another project, the Asia Forest Network, which Mark Poffenberger established, consisted of nearly five hundred community foresters in Southeast Asia and is now sustained by Rowena Soriaga of ESSC. Additionally much of that work is continuing with Mariel de Jesus, also

33 Manila Observatory, "MO Presents International Conference for 150th Anniversary," http://www.observatory.ph/2015/og/16/mo-presents-scientific-frontiers/ (accessed June 10, 2016).

34 N. Takeuchi et al., "Optical Properties of Some Aerosols Sampled in Asian Cities" (poster presentation at the 2000 Western Pacific Geophysics Meeting, Tokyo, Japan, June 2000), http://abstractsearch.agu.org/meetings/200o/WP/A42A-03.html (accessed June 10, 2016).

35 Other environmental science departments and/or centers of research in matters of sustainability are: China (Beijing Center, Macau Ricci Institute), Indonesia (Sanata Dharma University), Japan (Sophia University), Philippines (Ateneo de Davao University, Ateneo de Manila University, Ateneo de Naga University, Ateneo de Zamboanga, Xavier University), South Korea (Sogang University).

36 Earlier known as geographical information systems, this method creates layers with different sets of dates for the same geographic area that can also integrate remote sensing analysis and other global data sets. 
of ESSC, who is currently running the Philippine Working Group for community forestry and DRR. ${ }^{37}$

The Global Ignatian Advocacy Network (GIAN) facilitates five networks, with one specifically concentrated on ecology, and so is collaborating with academic and scientific institutions, such as the Stockholm Environment Institute and the Newman Institute, Uppsala (Sweden). By coming together and shaping a common ground, this consortium suggests that science alone will not provide solutions for a more sustainable world. ${ }^{38}$ Indeed, problem-focused science knows it needs to communicate its knowledge to billions of people and must do this through values so that people can reinterpret it locally, and accordingly might understand these changes within the wisdom of their culture and their context. As the document states, "Science gives us the rational arguments for guiding global decisions." ${ }^{39}$ Yet there is the matter of motivation and confronting the kinds of apathetic dispositions that object to being implicated in this moral dilemma. In recognition of the need for a deeper understanding of values, this collaborative project seeks to guide "this transformative process towards justice and healing within planetary boundaries." ${ }^{\text {40 }}$ Various elements that could enable this social transformation include the following: solidarity, spirituality, hope, depth, mindshift, and social inclusion. Accordingly, it is, on the one hand, personal and, on the other, should encompass both the social and political will toward greater economic accountability in order to sustain the natural flows of the planet for the generations to come. ${ }^{41}$ This document, moreover, offers the Society a potential platform for an intra-conference

37 For an array of perspectives of Philippine Working Group, see Environmental Science for Social Change, http://essc.org.ph/content/category/c27-philippine-working-group-forresource-management/ (accessed June 27, 2016).

38 GIAN-Ecology, http://www.ecojesuit.com/gian-ecology/ (accessed June 13, 2016); see also Global Ignatian Advocacy Networks (GIAN), Promotio iustitiae 110, no. 1 (2013): 25-27, http://www.sjweb.info/sjs/documents/PJ_110_ENG.pdf (accessed June 10, 2016).

39 "Broadening the Dialogue for Transformative Values: Attitudes, Simplicity, and Social Inclusion," Ecojesuit, last updated September 15, 2015, http://www.ecojesuit.com/ broadening-the-dialigue-for-transformative-values-attitudes-simplicity-and-social-inclu sion/8641/ (accessed June 13, 2016).

40 "Dialogue on Sustainability Science and Values: Seeking a Transformative Process," Ecojesuit, http://www.stockholmdialogue.ecojesuit.com/index.php/2015/10/03/dialogueon-sustainability-science-and-values-seeking-a-transformative-process/ (accessed June 13, 2016). For the final outcome of that dialogue, see "The Stockholm Dialogue: A Call to Sustainability Science and Values," https://issuu.com/ecojesuit/docs/stockholm_dia logue_briefing_kit (accessed June 13, 2016).

41 Conference on Transformative Land and Water Governance, 21-23 May 2014, http://trans formativegovernance.essc.org.ph (accessed June 13, 2016). 
exchange, particularly with South Asia, where numerous social and educational institutes are collaborating according to the agenda of the 2015 international conference, "Global Climate Change and Water Disasters." 42 Additionally, formal links are already achieved with European Jesuit institutions, such as the Université de Namur and Universidad Pontificia Comillas, and in Africa informally amongst several institutes that are involved in food, agriculture, mining, forestry, and water.

A greater focus on values can help to form a broader social engagement that is gravely lacking at this critical point, and that might guide our actions and decisions within the planetary boundaries. Through the promotion and deepening of this dialogue on transformative values, commitments can be reinforced for the benefit of a more sustainable world. The dialogue about sustainability science can share such human concerns, as well as for an urgent need to undergo a change in lifestyle, and for greater action when the environmental changes are experienced at the local level. This social commitment may motivate a greater response..$^{43}$

\section{A Call to Share Inner Life: Towards Simplicity}

Coming from the invitation to respond to reconciliation with creation, many Jesuits are increasingly more conscious of the broader web of life, and how one's decisions or actions affect others in this complex network of relations. ${ }^{44}$ Jesuits and partners in the Asia-Pacific region are accordingly moving towards sustainability and responding to the call for a simple lifestyle. Though many are struggling to achieve a more sustainable and simpler life, the shared learning is immense and people are continuing to adapt.

The environment and its degraded conditions may represent a pivotal point in the personal lives of many, and potentially in concurrence with the pursuit of a more dignified life for the majority of humanity. Such are the themes that centrally occupy today's global and local discussions about ecosystems. Many, such as overseas workers or the Rohingya people who at present are seeking refuge in Asia, are particularly vulnerable and so they are examples of those seeking this particular goal in the Asia-Pacific region. Many immigrants,

42 GIAN, South Asia, http://www.gianecologysa.com/EarthSummit.htm (accessed June 13, 2016).

43 This discourse can be followed on Ecojesuit: "Ecology and Jesuits in Communication," http://www.ecojesuit.com/gian-ecology/ (accessed June 13, 2016).

44 JCAP, "A Call to Inner Life and Simplicity," http://www.ecojesuit.com/wp-content/uploads/2014/11/JCAP.jpg (accessed June 13, 2016). 
tragically, die at sea in the hopes that they will be accepted, given asylum, and an opportunity to live a dignified life. Similarly, communities in the Philippines, neglected after Typhoon Haiyan devastated their homes and livelihoods, consist of many survivors who are still suffering from emotional distress amidst efforts to physically rebuild lives. ${ }^{45}$

An exemplary approach can be found in the Japanese and Korean Jesuit provinces, who took the goal of collaboration a step further. In September 2015, in conjunction with the Gangjeong Peace Conference, these provinces convened on the island of Jeju for the first plenary meeting of Jesuits and their collaborators from these two neighboring provinces. Amongst the contributors were Mitsunobu Ichiro, S.J. (b.1956), Kim Chong-dae, S.J. (b.1962), Munsu Park, S.J. (b.1941), Park Do-hyun Johann, S.J. (b.1962), and Ando Isamu, S.J. (b.1934). The island itself, with its unique terrain and its farming and fishing communities - symbols of peace in their homeland and yet, like Okinawa, having suffered as a result of international conflicts-was significant. This inter-provincial meeting also brought together citizens of two countries, which have numerous aging nuclear power plants that place the whole populace at risk and that do not require a tsunami to present a disaster. At this meeting, the two provinces established much common ground, especially with regarding environmental initiatives that aim to inhibit nuclear energy and to promote renewable energy. 46

Recognizing what is happening in the Pacific Islands, particularly with respect to sea-level change, Jesuit schools aim to achieve greater environmental awareness. This became a central facet of the pastoral agenda in Micronesia, as supported by Thomas Benz, S.J. (b.1965), Martin Carl, and Kevin Gerike. Antony de Brum, the foreign minister of the Marshall Islands and a former student of Xavier High School (Micronesia), further inspired their efforts as he called for a "high ambition coalition" at the Paris COP21 meeting in November 2015. ${ }^{47}$

45 "Peace Is Not Easily Found: Tacloban a Week after Typhoon Yolanda," Ecojesuit, November 29, 2013, http://www.ecojesuit.com/peace-is-not-easily-found-tacloban-a-week-aftertyphoon-yolanda/6o11/ (accessed June 13, 2016).

46 JCAP, "Collaborating for Peace and Justice in Japan and Korea," updated September 22, 2015, http://sjapc.net/content/collaborating-peace-and-justice-japan-and-korea (accessed June 13, 2016).

47 Karl Mathiesen and Fiona Harvey "Climate coalition breaks cover in Paris to push for binding and ambitious deal: Alliance representing more than 100 countries, including us, shows developed and developing world can work together, says Eu climate chief," The Guardian, December 8, 2015, https://www.theguardian.com/environment/2015/dec/o8/coalition -paris-push-for-binding-ambitious-climate-change-deal (accessed June 26, 2016). 
Witnessing the leadership of a local leader on an international stage, many of the youth who were celebrating Earth Week in the Marshall Islands, as a result, saw that their actions and voices do matter, and that it is possible to make a critical difference.

This kind of reflection also allowed Jesuits to assess their own participation at a communal level. For instance, Dominique Tyl, S.J. (b.1945), is already in the process of an initial analysis of middle-income families in Hong Kong and Taiwan in order to determine what Jesuit house budgets could manage, and what models they could possibly emulate. As a result, Jesuit institutions and communities are slowly open to a more comprehensive accounting of their ecological footprint, striving to strengthen this commitment through Ignatian spirituality that reflects a care for creation in a responsible lifestyle, through an institutional vision, and in practices that may enact such a vision. Filipino Jesuits, for their part, commited to establish more eco-friendly communities, are focusing on waste management as a means to reconciliation with creation. ${ }^{48}$

For a campus-wide perspective, Saint Ignatius' College, Riverview (Australia), can be regarded as exemplary case. Since 2008, it has held Earth Hour breakfasts for the school's environmental leaders, an occasion that enables conversations with other school leaders to go beyond Earth Hour. ${ }^{49}$ It is a great prompt for schools to know that they can connect through a worldwide event, and that students and teachers may return to their respective schools passing along various ideas in order to create change by caring for the environment. Sue Martin, the college's sustainability officer, Jennie Hickey of the Australian province, and Iris Legal of ESSC are also running a sustainability course for environmental managers of Jesuit campuses in the Asia-Pacific region. Chris Gleeson, S.J. (b.1943) of JCAP pre-secondary and secondary education also supports this endeavor.

Furthermore, Saint Ignatius' College hosted in July 2014 a JCAP education colloquium for Jesuit and partner schools on the theological theme of reconciling with creation. The program, entitled "The Planet Is Our Home," focused on three main areas: reconciliation with creation and spirituality; global reconciliation with creation; and reconciliation with creation and best practices.

48 JPAC, "Becoming Environment-friendly Jesuits Houses," June 23, 2016, http://sjapc.net/ content/becoming-environment-friendly-jesuit-houses (accessed June 13, 2016). In the Philippines, Mark Lopez, S.J. (b.1976) in particular has initiated this endeavor for his fellow scholastics.

49 Saint Ignatius's College, Riverview, "Our School Sustainability," http://www.riverview.nsw .edu.au/text-image/our-school-sustainability/ (accessed June 13, 2016). 
Participants included senior executive leaders, chairs and members of board, practitioners specializing in sustainability, sustainability educators, and principals and rectors across the Asia-Pacific region. ${ }^{50}$

Students at Wah Yan College in Hong Kong, with the support of their teachers (especially Mike Lai), provide a helpful example of a community engaging a specific issue, namely recycling food waste. Every day during lunchtime, a mass of food waste is produced and the majority of which would have been thrown away in the past. However, food waste can be useful fertilizer after interacting with certain microorganisms, and so Wah Yan College students seek to convey the message to their community that food waste can be a valuable commodity. Consequently, the school applied for funds from the environmental protection department at the Government of the Hong Kong Special Administrative Region in order to purchase a food waste decomposer, which started operating in March 2013. Afterwards, official food waste "ambassadors" organized each class to assist this campaign, and currently food waste is collected from each class and in the cafeteria for decomposition. ${ }^{51}$

This trend towards "greening" Jesuit campuses, which is occurring from Australia to East Timor, is simultaneously informing the Society of Jesus itself on best practices. It is especially helpful in the project to design the first Jesuit high school that aims to be comply with sustainable, "green" standards. Situated on the Kok River, a tributary of the Mekong, this school is intended to serve indigenous communities in the northern hills of Thailand. Peter Pichet Saengthien, S.J. (b.1974), a Thai Jesuit, is assuming responsibility for this project. $^{52}$

In addition to a project like Saengthien's, other Jesuits are making ecology a central aspect of their own missions. Albert Alejo, S.J. (b.1958), for example, works with cultural politics and indigenous peoples in contested environments, specifically in Mindanao, Philippines. Joseph Fung, S.J. (b.1954) coordinates the Jesuit Companions in Indigenous Ministry across Asia-Pacific. Working in these areas is difficult due to the grave social injustice and social exclusion that emerge as a result of the apparent contradictions in the present world order. Moreover, such conditions tend not only to neglect indigenous wisdom

50 JCAP Colloquium, http://www.jcapcolloquium.org (accessed June 13, 2016).

$5^{1}$ "Students in Hong Kong Shows that Food Waste Is Not Rubbish," Ecojesuit, July 4, 2013, http://www.ecojesuit.com/students-in-hong-kong-show-that-food-waste-is-not-rub bish/5436/ (accessed June 13, 2016).

$5^{2}$ Peter Pinchet Saengthien, S.J., "Building a Green School in Thailand's Northern Uplands," Ecojesuit, May 31, 2015, http://www.ecojesuit.com/building-a-green-school-in-thailands -northern-uplands/7880/ (accessed June 13, 2016). 
traditions, particularly with regards to the land and sea, but often enable the exploitation of natural resources, upon which these indigenous communities depend. Joel E. Tabora, S.J. (b.1947) confronted the impact of mining in both the Bicol Region, where fisher-folk were becoming harmed, and in Mindanao, where the indigenous communities and local farmers were being displaced for the sake of a proposed copper mine. As a result, GIAN's Justice in Mining network, coordinated by Julie Edwards (Jesuit Social Services) in Australia, is aiming to support local efforts where it is possible to investigate injustice, while also examining the socio-environmental effects of mining from a global perspective.

Along these lines, a variety of projects that fall under JCAP's social apostolate are assuming a distinctively environmental character. In Cambodia, Gabby Lamug-Nañawa, S.J. (b.1969), initiated in 2012 a carbon offset program in conjunction with the modest seedling nursery that was established in Banteay Prieb, the Jesuit-run vocational school for people with disabilities. ${ }^{53}$ Elsewhere, in East Timor, E. J. Gerilla, S.J. (b.1977), Albino Goncalves, S.J. (b.1982), and Julio Sousa Costa, S.J. (b.1986), are collaborating with communities by focusing on their social needs - specifically in this case, water accessibility — and their collective livelihood, intertwined as it is with the environment. Vincent Lin, S.J. (b.1977), Teresa Tao, and Fernando Azpiroz, S.J. (b.1967), are striving to understand the environmental needs of communities in China, especially around issues concerning domestic water. Benedictus Bambang Triatmoko, S.J. (b.1965), initiated in various part of Indonesia programs that encourage communal livelihoods in the cultivation of jatropha for ethanol and seaweeds for agar. Sustainable livelihoods, ecologically sound agriculture, and agroforestry are key concepts requiring further attention and development.

The challenge of climate change, as Pope Francis illustrated in Laudato si', is now fully public and is revealing that all aspects of life demand deeper reflection. First of all, there is an imperative to recognize in this globalized era those interconnections that bind, and that such relations should call people into dialogue about the ecological state of "our common home."54 The presence of the Holy Father at many crucial global meetings, with clear statements of exhortation, explicating this dialogical intent, may lead to a potential turningpoint - reflected not only for necessary shifts in global policy, but also for the breadth of social engagements that the current moment demands.

53 JCAP, "A Jesuit Carbon Offset Programme in Cambodia," April 22, 2014, http://sjapc.net/ content/jesuit-carbon-offset-programme-cambodia (accessed June 13, 2016). 
In Asia-Pacific, those seeking change are receiving the encyclical's message, which has greatly contributed to the growing ecological awareness and sense of care for the Earth as an integral part of Christian responsibility. Pope Francis's call for action presents an occasion for people who are already deeply involved in communities of practice to express a much broader and deeper solidarity through global events and social media. Such expressions can be increasingly described as signs of "ecological citizenship." ${ }^{5}$ Though the necessary change cannot not achieved immediately, collective action and concentration upon local areas of commitment may allow for a deepening of hope and perseverance.

In Asia-Pacific, it is also clear that the promulgation of Laudato si' has affected a process of discernment about what is "enough," and provides an opportunity to reflect upon creation in daily life while enjoying the local terrain as a place for experiencing God's living presence. During Francis's own visits to this region, for instance, in South Korea, where he encouraged peace and reconciliation, ${ }^{56}$ and in the Philippines, where he accompanied those who suffered great loss in the typhoons, the Holy Father gently affirmed and reminded his audience of survivors of Typhoon Yolanda that Christ's presence can still be known in these disasters. ${ }^{57}$ This exemplifies the kind of radical call for social inclusion in the Asia-Pacific context that might combat the globalization of indifference. Furthermore, he instructs that through an attitude of giving that emanates from a deep gratitude to God for creation, we might share the hope of the crucified Christ, "who cries with us, walks with us even in the most difficult moments of life." 58

Such a spirituality and discernment that reaches out to the vulnerable represents a sense of solidarity with the marginalized that might even include the environment itself. Pertaining to the pastoral mission of the Society in Asia-Pacific, such spiritual direction indicates that "the God of the living is also the God of how we live."59 This might be exemplified in the attitudes of the

55 Ibid., n. 211.

56 Vatican News, "Apostolic Journey of Pope Francis to the Republic of Korea on the Occasion of the 6th Asian Youth Day," June 18, 2014, http://www.news.va/en/sites/pope-francis -korea-august-13-18 (accessed June 13, 2016).

57 Pedro Walpole, "Flooding and God: Spirituality and Disaster in the Philippines after 25 Years," unpublished.

58 “I Have No More Words for You," La Stampa (January 17, 2015), http://vaticaninsider.lastampa.it/en/world-news/detail/articolo/francesco-filippine-38595/ (accessed June 13, 2016).

59 Pedro Walpole, "Do Not Be Afraid: Laudato si' and Integral Ecology," The Way 54, no. 4 (2015): 9-22. 
poor who know with humility that they are constantly dependent upon God's mercy for their daily food. While the Holy Father presents this perspective in spiritual language, in a secular context he is openly challenging every person to move beyond the comfort of indifference and towards an understanding of care that may expand their sense of compassion and solidarity towards spiritual affirmation.

\section{Our Strategic Engagement}

Action, for many Jesuits, occurs out of a deepening experience of "finding God in all things," which is a basic principle of Ignatian spirituality. ${ }^{60}$ Based on this way of proceeding, it is then easy to understand how in 2011, in the teaching document Reconciliation with Creation, Superior General Adolfo Nicolás, S.J. (b.1936), asked Jesuits to put their own house in order, environmentally speaking, before going out into the world. In a similar manner, Pope Francis called us to be globally responsible, as he is seeking in his own administration to achieve a net carbon zero footprint in the Vatican. ${ }^{61}$ As for Jesuit communities and their apostolic works, a more sustainable lifestyle is still a goal to be attained per recommendations of Healing a Broken World. This, of course, may manifest through various forms that are particular to their own education, research, and formation so that they might engage students in a transformative kind of education. As Jesuits have begun to respond to this call for an integral ecology, they may be aided through several innovative initiatives.

\section{Green-Building Audit and Lifestyle in Jesuit Houses and Communities}

The international houses of the East Asian Pastoral Institute and the Arrupe International Residence, for example, are conducting a rapid assessment of their

6o Faithful and Free, a Generous Spirit Ablaze with God: The Constitutions of the Society of Jesus, Annotated and Complemented by General Congregation 34, ed. Parmananda R. Divarkar (Anand: Gujarat Sahitya Prakash, 1997), ch.1, n. 26 [288].

61 Stephanie Kirchgaessner, "Vatican may consider divestment from fossil fuels despite pope's call to arms," The Guardian (July 1, 2015): http://www.theguardian.com/environment/2015/jul/o1/vatican-may-consider-divestment-from-fossil-fuels-despite-popes-callto-arms (accessed June 13, 2016). Such a goal accordingly necessitates divestment of both armaments and fossil fuels. 
buildings, seeking to develop a form of operational management that is respectful of the environment. Generally speaking, existing policies, procedures, and ecological practices in many of the Jesuit institutes are often forgotten and not consistently modified on an annual basis. Better documentation of operations, procedures, and responsibilities may help to sustain a more fully ecological plan of action through the shared efforts of both management and residents. Such a communal challenge to consciously record and monitor resources with a vision towards sustainability might only be sustained through the regular assessment and participation of all community members.

From this perspective, communities are inspecting the infrastructure of Jesuit communities with respect to drainage, waste disposal facility, ventilation, lighting, and landscaping practices. Particularly in urban areas, there is an obvious desire to obstruct dust, rain, and even light in order to create an ambience that is appropriate for a workspace; nevertheless, this tends to prioritize air-conditioning that might obscure a basic sense of connection with nature, and simultaneously a solidarity with how their neighbors must live. ${ }^{62}$ Accordingly, some Jesuits are discerning the possible use of new technology and new practices especially with respect to energy, water, and waste. In this effort, a working document, entitled "Auditing Sustainability of Our Buildings and Communities," is providing a kind of sustainability checklist. ${ }^{63}$ Still, there is the need to attend to the necessary shift in attitude, especially to cultivate the capacity to seek simplicity as a form of witnessing.

Another manifestation of this impulse, a voluntary carbon offset contribution was affirmed through the "Flights for Forests" that started in the Philippines, then was developed in Cambodia and has since spread to East Timor, where local youth are planting community trees that relate to local needs. ${ }^{64}$ This program requests the participation of all Jesuits and their lay collaborators, by acknowledging the negative impact of air travel and also identifying environmental projects that may support rural communities that global

62 Francis, Laudato si', n. 55 .

63 JCAP, "Auditing Sustainability of Our Buildings and Communities," http://www.ecojesuit .com/wp-content/uploads/2014/10/Auditing-sustainability-of-our-building-and -communities.jpg (accessed June 13, 2016).

64 See JCAP, "Flight for Forests," http://www.ecojesuit.com/wp-content/uploads/2014/11/F3 -Flyer_May19.pdf (accessed June 13, 2016). With aviation accounting for four to nine percent of the climate change impact of human activity and recognizing that the Jesuit mission requires many to fly frequently for meetings, JCAP created a carbon-offset program, Flights for Forests. All Jesuits and partners within JCAP can participate by contributing five USD for every flight taken, to compile those flights up over a six-month period, and to submit the corresponding finances. 
economics and climate change harm the most. ${ }^{65}$ Youth groups in rural parts of Asia-Pacific subsequently use the financial contributions for forest renewal activities.

\section{Transformative Courses}

For many of our partners and participants, including scholastics, greater cultivation of capacity and leadership skills are sought as they engage in the ethical scheme of reconciliation with creation. Many recognize the need for an integrated curriculum that engages science and theory while also instilling a deep sense of spirituality, ethics, and values. Practical experiences and social engagements are essential in order for people to address the emotional need that this particular problem presents, as well as the ability to collaborate, the skills of accompaniment, the development of their own social analysis, and the renewal of their spirituality.

Michael Garanzini, S.J. (b.1948), now at the Jesuit Curia in Rome, initiated the International Jesuit Ecology Project (IJEP), a project that is global in scope, and subsequently developed Healing Earth, a free online textbook for environment science for upper-level secondary school and rising college students. ${ }^{6}{ }^{6}$ This text addresses major ecological challenges of our time from integrated scientific, spiritual, and ethical perspectives. Nancy Tuchman, Michael Schuck, and other experts in science, spirituality, and ethics from the six conferences of the Society of Jesus provide the expertise and motivation to sustain IJEP. The first edition, launched in January 2016, includes chapters on biodiversity, natural resources, energy, water, and global climate change. A Teacher's Guide, another resource, is available to facilitate educators in the instruction of the environmental sciences as they develop classes in the areas of ethics and spirituality. Many in the Asia-Pacific region contributed to Healing Earth, which the Association of Jesuit Colleges and Universities-Asia Pacific also formally adopted.

Another facet of JCAP's curriculum development is the outdoor course, "The Human Development and Natural Resource Management," which is offered in conjunction with the Asian Peacebuilders Scholarship program that is the product of University for Peace-a United Nations venture - and Ateneo de

65 http://sjapc.net/what-we-do/flights-forests.

66 Loyola University Chicago, "International Jesuit Ecology Project," http://www.luc.edu/ ijep/ (accessed June 13, 2016). 
Manila University. ${ }^{67}$ Coordinated by Jose M. Cruz, S.J. (b.1949), vice president for the university and global relations, this course is offered in the Philippines to young professionals and master's degree students in Asia in order to learn, on the one hand, some of the most important global agreements concerning the environment and, on the other hand, topics that are related to sustainable development and human development. Through the course, students have the opportunity to explore various approaches to natural resource management in Asia and the required modes of integration in order to achieve environmental and human security. Rodolfo Ang, the dean of the Ateneo Graduate School of Business, has emphasized the importance of integrating sustainability in business courses for young executives.

For the JCAP Scholastics and Brothers Circle, a two-week engagement with people and the landscape on DRR and management was organized with particular focus on the Jesuit protocol on DRR in Asia-Pacific to understand the role of Jesuits, and more broadly Jesuit institutions, in disaster management. 68 There is a growing consciousness within the conference that Jesuits, in particular, need to engage in the broader DRR process and to collaborate with other institutions, as well as to clarify their own role in both humanitarian and development work. Accordingly, this assembly reflected upon on the experience in Leyte, where communities suffered gravely from Typhoon Haiyan in November 2013, especially as a result of the storm surge, high winds, and flooding. They concentrated on DRR in the various scenarios of drought, fire, volcanic eruption, earthquake, and nuclear meltdown, that subsequently expanded the range of disasters that communities may confront.

Given the sustained social vulnerability of many in Asia-Pacific, it became evident that the problem might lay deeper and that faith may be the primary source of healing, in interconnecting the spirit of trust in God and the hope of the community. In attesting to how hope works, the participants also gained hope themselves, and as a result many scholastics are beginning to envision the church in a different light, as a life-giving and humble presence. An example of such an ecclesial presence might be available in the Philippines, specifically at the Culture and Ecology Center of the Apu Palamguwan Cultural Education Center. Responding to the increased need to organize and manage an integrated learning center, this initiative coordinates the different environmental

67 Ecojesuit, "Sustainability Camp: UPEACE 2014," June 10-20, 2014, http://www.ecojesuit .com/sustainability-camp/ (accessed June 13, 2016).

68 JCAP, "Jesuit Conference of Asia Pacific: Developing a Coordination Protocol for Disaster Risk Reduction and Management," last modified January 2015, http://www.ecojesuit.com/ wp-content/uploads/2014/11/JCAP-DRR-Protocol_Jan2015.pdf (accessed June 13, 2016). 
programs for groups throughout Mindanao in conjunction with the local Bendum community, who as an indigenous group possess ancestral rights. Such a venue can become a place for the fruitful convergence of people, ideas, and experiences that would provide space for personal learning and reflection. ${ }^{69}$ Still such values and visions are yet to be demonstrated as effective tools in building a more sustainable integral ecology.

\section{Eco-Networking and Communication}

Eco-networking and communication play a crucial part in sustaining and bringing Jesuit initiatives and ministries into a broader global and social action as a venue for interconnectivity and collaboration. Ecojesuit, or Ecology and Jesuits in Communication, for instance, is a project that was initiated collaboratively by the Jesuit European Social Centre (JESC) and JCAP, and is now an online presence that currently communicates in Spanish, English, and French, with contemporary and original commentaries, reflections, analysis, exchanging ideas and best practices on various ecological and social concerns. ${ }^{70}$ Conducting a discourse on the concerns of communities from different regions, while strengthening the scientific knowledge that informs such actions and responses, Ecojesuit is basically a communications strategy. Nonetheless, within the Society as a whole, there is still much internal resistance to such adaptive measures. Consequently, Ecojesuit aims to share signs of hope and positive processes. Its proliferation in this particular article reflects the cross-cultural dynamics that such a platform provides, bringing different perspectives to the forefront. In a different capacity, the JCAP e-News bulletin, which Karen Goh edits, delivers these messages and ideas to a broader audience. ${ }^{71}$

\section{Conclusion}

Much hope is expressed in writing this article, though it humbly recognizes that Jesuit environmental activities are still very limited — though this it is not the occasion to provide an in-depth analysis of that phenomenon. Most of the

69 Kay Pitman, "Bendum, an Emerging Center for Ecology (2013)," February13, 2013, Apu Palamguwan Cultural Education Center website, http://apupalamguwancenter.essc.org $. p h / ? p=788$ (accessed June 13, 2016).

$70 \quad$ Ecojesuit, http://www.ecojesuit.com (accessed June 13, 2016).

71 JCAP e-News, http://sjapc.net (accessed June 13, 2016). 
material that is being generated is web-based and aims to reflect the current exchange of ideas at this nascent stage of engagement, and that might also be suitable to correspond with the desired accessibility and increased shareability. Thus, it is hoped that the experience of JCAP can compensate slightly for what is still lacking. ${ }^{2}$ Many Jesuits continue to struggle apostolically in reflecting upon and sharing their sense of interconnection with the land and broadly with the full breadth of forms of life around them as well as the management of natural resources that they oversee. Many are asking how their individual works of reconciling with creation can relate with a broader plan of action and research.

Networks today are challenged to go beyond a loose association of shared interests in order to seek further active participation. They need to acknowledge institutional autonomy and foster participation, greater generosity, and collective commitment to focused action. ${ }^{73}$ While Jesuits are in the process of building networks that are inclusive of others, they should also engage broadly with networks beyond the Society, with whom they might play important roles in collaborative projects. Pope Francis, for his part, emphasized that a "science which would offer solutions to the great issues would necessarily have to take into account the data generated by other fields of knowledge, including philosophy and social ethics." ${ }^{74}$ At this juncture, theology and spirituality still need to be challenged in order to engage science.

Jesuits can still contribute to this dialogue and facilitate greater understanding and commitment. Given the political failure that occurred in the aftermath of COP15 (2009) in Copenhagen, COP21 (2015) in Paris represents a recovery especially concerning Intended Nationally Determined Commitments (INDCs), a type of new international agreement that outlines post-2020 public actions and goals. In Asia-Pacific, nearly every country, including China, has agreed to participate. ${ }^{75}$ On the provincial level, JCAP convened with collaborators for a

72 See UnEsco, "Belém Framework for Action: Harnessing the Power and Potential of Adult Learning and Education for a Viable Future," in Confintea vi: International Conference on Adult Education (Hamburg: UnEsco Institute for Lifelong Learning, 2010), 5-9, esp. 5-6, http://unesdoc.unesco.org/images/oo18/oo1877/187789m.pdf (accessed June 13, 2016).

73 "Networking for Justice: Gathering of Global Jesuit Networking from the Social Apostolate; Final Document," Loyola, Spain, November 17-20, 2015, https://jesuitnetworking.org/ wp-content/uploads/2015/11/151120_FINAL_DOC.pdf (accessed June 13, 2016). See also Jesuit Networking, http://jesuitnetworking.org/ (accessed June 13, 2016).

74 Francis, Laudato si', n. 110.

75 For the Copenhagen meeting, see United Nations Framework Convention on Climate Change (UNFCC), http://unfccc.int/meetings/copenhagen_dec_2009/meeting/6295.php (accessed June 13, 2016). For the most recent cop convention, see UNFCcC, http://unfccc. 
workshop that reflected upon the guidance of Laudato si' and the importance of INDCs for integrating global and moral strategies at the local, grassroots level. ${ }^{76}$ In the aftermath of the workshop, the group acknowledged the challenge to gain a more integral understanding of the world and the need for a deeper dialogue that can exchange human values.

Thus, it might be fitting to conclude with the guiding reflections of the Holy Father on the current global state of affairs:

Human beings, while capable of the worst, are also capable of rising above themselves, choosing again what is good, and making a new start, despite their mental and social conditioning. We are able to take an honest look at ourselves, to acknowledge our deep dissatisfaction, and to embark on new paths to authentic freedom. ${ }^{77}$

int/meetings/paris_nov_2015/meeting/8926.php (accessed June 13, 2016). CAIT Climate Data Explorer-World Resources Institute http://cait.wri.org/indc/\#1 (accessed June 13, 2016). United Nations Framework Convention on Climate Change, "Aggregate Effect of Intended Nationally Determind Commitments: An Update; Synthesis Report by the Secretariat," May 2, 2016; available online at: http://unfccc.int/focus/indc_portal/items/9240. php (accessed June 13, 2016).

76 JCAP, "Renewing Life and Mission in Ecology," June 23, 2016, http://sjapc.net/content/ renewing-life-and-mission-ecology (accessed June 27, 2016).

77 Francis, Laudato si', n. 205. 